\title{
Dentists’ Health Influencing Psycho-Physiological Factors during Work
}

Antons Maksimovs*

Faculty of Dentistry, Riga Stradins University, Riga, Latvia

"Corresponding author: Maksimovs A, Faculty of Dentistry, Riga Stradins University, Riga, Latvia. Tel: +37128381800; E-mail: maksimovs.a@inbox.Iv Rec date: October 27, 2017; Acc date: November 16, 2017; Pub date: November 20, 2017

Copyright: (c) 2017 Maksimovs A. This is an open-access article distributed under the terms of the Creative Commons Attribution License, which permits unrestricted use, distribution, and reproduction in any medium, provided the original author and source are credited.

\begin{abstract}
Introduction: During the research, 150 dentists were interviewed. According to the results, it is possible to subjectively evaluate the situation among dentists in Latvia. The results from this study coincide with several researches made by other scientists in terms of this subject. In general, their results are similar to the conclusions of this work.

Purpose: The aim is to examine problems, which affect professional dentists' health, using survey results and other authors' researches.

Methods: Empirical data collection method was applied. A survey with 15 questions about the topic: "Is it healthy to be a dentist?" was made, and 150 dentists were interviewed to determine, how working conditions affect dental health.

Results: $30 \%$ of respondents have more than 20 years of work experience. $25 \%$ of respondents have $10-20$ years of work experience, but for $45 \%$ it's less than 10 years. Respondents were aged between 22 and 73 years, but work experience ranges from 6 months to 49 years. $66.6 \%$ of the interviewed are women, but $33.3 \%$ are men. $7.7 \%$ work less than 20 hours per week, $28.2 \%$ work $20-30$ hours per week, $20.5 \%$ of the interviewed work $30-40$ hours per week, 38.5\% work 40-50 hours per week, and $5.1 \%$ work more than 50 hours per week. $90 \%$ of dentists feel pain after work. The pain is mostly located in the back (respondent's note that in lumbar and neck regions pain focuses the most), head, arms and legs.

Conclusions: In dentists' work, there are many professional psycho-physiological factors, which heavily influence dentist's health. Surgical Dentists usually stand while working, but dental therapists are sitting, but almost all the time they occupy awkward and uncomfortable sitting posture. Despite the fact that dentists work in well-lit rooms, more than one third notices vision decrease.
\end{abstract}

Keywords: Psycho-physiological factors; Dentist; Health; Ergonomic; Posture

\section{Introduction}

A professional dentist is a hard job. Dentist Professionalism grows up with age. Unfortunately, health deteriorates faster than experience and professionalism grows. Minimal deviations from normal working conditions accumulate over time and lead to consequences that can partly or completely determine the future of the dentist.

In the work of dentists there are several psychophysiological factors affecting their health, mainly three main: long sitting or standing, static load on their hands and increased tenseness of vision. Failure ergonomics during work, leads to musculoskeletal disorders.

- Professional factors group's affects dentist health:

- Physical factors (vibration, noise, and ultrasound)

- Chemical factors (time intoxications, chronic intoxications)

- Biological factors (pathogenic microorganisms)

- Psycho physiological factors (prolonged sitting, uncomfortable standing, static load on the hands, and increased eye strain).
At the dentist work, the load on the spine increased by 1.6 times, but when dentist work with the curve, the load increases 4 times, while working on legs with the curve, loads on spine increases 10 times. Long-term work in this unergonomic position leads to such problems as: deformation of the back and legs, flat foot syndrome and varicose veins. The prolonged sitting time leading to kyphosis, scoliosis can lead to stagnation of blood in the abdominal cavity and rectal veins, anemia, hemorrhoids and other diseases. The wrong posture affects the intervertebral discs negatively. A tilting seat can cause increased pressure on the intervertebral disc, which can lead to a herniated disc.

\section{Main Lumbar Diagnoses}

- Sciatic

- Pyriformis Syndrome

- Lumbar vertebra DDD (Degenerative disc disease)

- Lumbar vertebrae osteoarthritis

- A disc hernia

- Sacroiliac Joint Dysfunction

- Paraspinal muscle spasm 


\section{Main Throat Diagnosis}

- Neck DDD (Degenerative Disc disease) shown in Figure 1.

- Neck osteoarthritis

- Cervical radiculitis

- A disc hernia

- Muscle spasm

- Thoracic Outlet Syndrome

Dental work is associated with natural and artistic lighting. Good illumination of the workplace helps to provide filament lamps, fluorescent lamps, xenon reflectors. Artificial lighting can cause visual fatigue, accommodation spasm, and myopia.

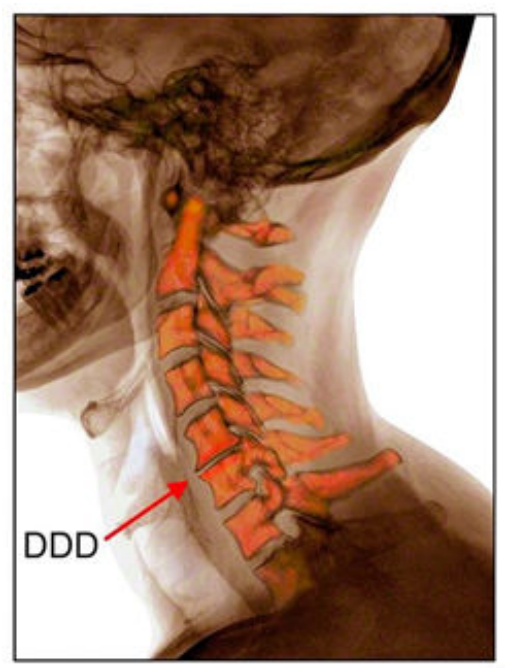

Figure 1: Degenerative disc disease [1].

\section{Subjects and Methods}

Empirical data collection method was applied. A survey with 15 questions about the topic: "Is it healthy to be a dentist?" was made, and 150 dentists were interviewed to determine, how working conditions affect dental health.

\section{Results}

Analysis of obtained data makes it possible to look at few dentists professional problems that affect their health. $30 \%$ of respondents have more than 20 years of work experience. $25 \%$ of respondents have $10-20$ years of work experience, but for $45 \%$ it's less than 10 years. Respondents were aged between 22 and 73 years, but work experience ranges from 6 months to 49 years. $66.6 \%$ of the interviewed are women, but $33.3 \%$ are men. $7.7 \%$ work less than 20 hours per week, $28.2 \%$ work $20-30$ hours per week, $20.5 \%$ of the interviewed work 30-40 hours per week, 38.5\% work $40-50$ hours per week, and $5.1 \%$ work more than 50 hours per week. $90 \%$ of dentists feel pain after work. The pain is mostly located in the back (respondent's note that in lumbar and neck regions pain focuses the most), head, arms and legs [2-7].

Deteriorated eyesight is noted by $35 \%$ of dentists, which is explained by fine manipulations done every day. $26 \%$ of dentists experience numbness in hands after finishing work, 18\% admits that they feel sickness, imbalance or dizziness after work [8-13].

More than a half $(56 \%)$ visit their doctor due to musculoskeletal disorders-mostly it's neurologist, physiotherapist or vertebrologist 1-2 times a year (educational courses). $96 \%$ engage in physical activities. The most popular (48.7\%) physical activity among respondents is gymnastics, then come swimming (28.2\%) and running (23.1\%). $35.9 \%$ of interviewed do massages as a rehabilitation measure. From 144 dentists, 75\% do physical activities 1-3 times a week, but 23\% 4-5 times a week. $77 \%$ of dentists suggest to reduce working hours to decrease the work affection on their health.56\% suggest to do physical activities during work time, $30 \%$ suggest to modernize and provide a more ergonomic working environment [13-17].

\section{Discussion}

- A total of 36 dentists with osteochondrosis had headache, 7 of them were chronic, 29 episodic. 30 patients developed pain in the neck, 11 had an arm tingling and paresthesia in the morning. The neck part spondylosis was found among 68 (52.1\%) dentists, $14.3 \%$ had thoracic spondylosis. 29 dentists (22.3\%) had spinal changes in the lumbar spine. After the research findings, it was concluded that dental work can be considered a very difficult job. Between 147 dentists, $38 \%$ of young dentists and $68 \%$ of dentists with work experience had skeletal and muscular disorders. The back, neck, shoulder pain and headache were detected in $81 \%$ of dentists, even if the working position was changed. Changing the position of a dentist does not change the frequency of pain, but only the localization of pain [18].

\section{Dentists need to follow certain steps}

- After every two hours, rest should be 10-15 min, after each patient 2-3 min rest, every 30-60 min break in the middle of the working day.

- Regularly engage in sports, physical activity, once a week swimming and massage.

- Daily 8 hour sleep. The bed should not be too soft.

- During work, use a chair with adjustable height, with backrest and headrest recommended to work in "four hands" with an assistant.

- Over $80 \%$ of the time, the dentist should work while sitting ergonomically correct posture is, if the head, neck, chest and abdomen are located on the same vertical axis, and the main load lies on the spine, and the muscles and ligaments are minimally used.

- Dentist should use comfortable instruments with a handle corresponding to the anatomical shape of the hand.

- Correct position of the legs: the legs should be relaxed and full surface should be on the floor.

- Put on comfortable shoes.

- Do regular exercises to improve your vision $[2,3,5,17]$.

\section{Conclusion}

- In dentists' work, there are many professional psycho-physiological factors, which heavily influence dentist's health. Surgical Dentists usually stand while working, but dental therapists are sitting, but almost all the time they occupy awkward and uncomfortable sitting posture. Despite the fact that dentists work in well-lit rooms, more than one third notices vision decrease. Almost all 
Citation: Maksimovs A (2017) Dentists' Health Influencing Psycho-Physiological Factors during Work. Gen Med (Los Angeles) 5: 304. doi: $10.4172 / 2327-5146.1000304$

Page 3 of 3

respondents were engaged in sports or some other physical activity, a third choose a massage that significantly rehabilitates the deteriorated health during the work. Almost all dentists noticed that working hour's decline of the day might improve their health; half of the respondents agree that a small gymnastics during work will relieve excessive fatigue and muscle tension.

\section{References}

1. https://www.pinterest.com/pin/350858627193145993/

2. Breitenfelder J (1975) Cervical osteochondrosis and spondylarthrosis, an occupational disease of the dentist? Z Orthop Ihre Grenzgeb 649-651.

3. Hagberg M, Hagberg C (1989) Occupational hazards in the health professions.

4. Katevuo K, Aitasalo K, Lehtinen R, Pietila J (1985) Skeletal changes in dentists and farmers in Finland. Community Dent Oral Epidemiol 13 23-25.

5. Yumashev GS, Furman ME (1984) Osteochondrosis of the spine (2nd ed). Moscow.

6. Kachesov VA (1998) Clinical manifestations and some methods of prophylactic prophylaxis of stomatology-osteochondrosis and humeropathy periarthritis. New in dentistry 4: 65-71.

7. Vodanović M, Sović S, Galić, I (2016) Occupational health problems among dentists in Croatia. Acta Stomatol Croat 50: 310-320.

8. Prudhvi K, Raja K, Murthy V (2016) Self-reported musculoskeletal pain among dentists in Visakhapatnam: A 12-month prevalence study. Indian J Dent Res 27: 348-352.

9. Khosravanifard B, Rakhshan V, Sherafat S, Najafi-Salehi L (2015) Risk factors influencing dentists' hepatitis B-related knowledge and attitudes and their willingness to treat hepatitis B positive patients. East Mediterr Health J 21: 54-61.

10. Andrew NG, Hayes MJ, Polster A (2016) Musculoskeletal disorders and working posture among dental and oral health students. Healthcare 4: 13.

11. Hodacova L, Sustova Z, Cermakova E, Kapitan M, Smejkalova J (2015) Self-reported risk factors related to the most frequent musculoskeletal complaints among Czech dentists. Ind Health 53: 48-55.

12. Cho K, Cho HY, Han GS (2016) Risk factors associated with musculoskeletal symptoms in Korean dental practitioners. J Phys Ther Sci 28: 56-62.

13. Kozak, Agnessa et al (2014) Self-reported musculoskeletal disorders of the distal upper extremities and the neck in German veterinarians: A cross-sectional study. PLoS ONE 9: e89362.

14. Feng B, Liang Q, Wang Y, Anderson LL, Szeto G (2014) Prevalence of work-related musculoskeletal symptoms of the neck and upper extremity among dentists in China. BMJ Open 4: e006451.

15. Koneru S, Tanikonda R (2015) Role of yoga and physical activity in workrelated musculoskeletal disorders among dentists. J Int Soc Prev Community Dent 5: 199-204.

16. Aghilinejad M, Kabir-Mokamelkhah E, Talebi A, Soleimani R, Dehghan $\mathrm{N}$ (2016) The effect of magnification lenses on reducing musculoskeletal discomfort among dentists. Med J Islam Repub Iran 30: 473.

17. Rafie F, Zamani Jam A, Shahravan A, Raoof M, Eskandarizadeh A (2015) Prevalence of upper extremity musculoskeletal disorders in dentists: Symptoms and risk factors. J Environ Pub Health.

18. Valachi B, Valachi K (2003) Mechanisms leading to musculoskeletal disorders in dentistry. J Am Dent Assoc 134: 1344-1350. 